\title{
Phase response analysis of a morphological globus pallidus neuron model during irregular spiking: intrinsic and synaptic mechanisms Nathan W Schultheiss*, Jeremy R Edgerton and Dieter Jaeger
}

\author{
Address: Biology, Emory University, Atlanta, GA 30322, USA \\ Email: Nathan W Schultheiss* - nschult@emory.edu \\ * Corresponding author
}

from Eighteenth Annual Computational Neuroscience Meeting: CNS*2009

Berlin, Germany. 18-23 July 2009

Published: 13 July 2009

BMC Neuroscience 2009, 10(Suppl I):P227 doi:I0.I I86/I47|-2202-I0-SI-P227

This abstract is available from: http://www.biomedcentral.com/I47I-2202/I0/SI/P227

(C) 2009 Schultheiss et al; licensee BioMed Central Ltd.

\section{Introduction}

Recent evidence suggests a prominent role for the globus pallidus (GP) in the synchronization of basal ganglia oscillatory activity associated with Parkinson's disease. The emergence of synchronous network activity is strongly influenced by the character of the phase response curve (PRC) that describes how a rhythmically spiking neuron responds to synaptic inputs by advancing or delaying the next spike. The PRC for dendritic inputs (dPRC) to GP contains both positive and negative regions, indicating that excitatory dendritic input can either advance or delay the next spike depending on when it occurs during the intrinsic spike rhythm. However, in vivo GP neurons receive stochastic backgrounds of synaptic input that drive irregular spiking. In this study, we investigated the interaction of stochastic synaptic backgrounds with intrinsic currents in the dendritic membrane of a morphologically realistic GP neuron model to assess how in vivo-like high conductance states affect dendritic phase response properties.

\section{Methods}

500 GABAergic and 100 AMPAergic synapses with maximal conductances of $250 \mathrm{pS}$ and mean activation frequencies of $0.5 \mathrm{~Hz}$ and $20 \mathrm{~Hz}$, respectively, were distributed randomly throughout the morphology of the GP model. The strength of the synaptic background was adjusted by multiplying the maximal conductances of all AMPA and GABA synapses by a gain factor, and AMPA and GABA reversal potentials were adjusted to keep the mean spike frequency constant for different synaptic background strengths. To assess the contribution of active dendritic conductances to the shape of dPRCs, we varied dendritic conductance densities around their baseline values.

\section{Results and conclusion}

Figure 1 illustrates perturbations (colored traces) of the control voltage trajectory (black trace) by inputs delivered during the first spike cycle. These inputs yielded long-lasting changes in spike pattern for weaker synaptic backgrounds (gain $=2$ ), but strong synaptic backgrounds (gain $=6$ ) forced spiking quickly back to the control trajectory.

Increasing the dendritic density of the small conductance calcium-activated potassium channel, SK, decreased spike advances and increased delays evoked by dendritic inputs, resulting in a negative shift of the dPRC. Increasing dendritic spike currents (fast sodium $(\mathrm{NaF})$ and the delayed rectifier (Kdr)), increased both spike advances and delays evoked by dendritic inputs at different phases of the spike cycle, doubling the amplitude of the dPRC. These modulations of active dendritic properties affected dPRCs similarly in high conductances states as in rate matched oscillators, suggesting that synaptic drive does not eliminate the complex influence of intrinsic dendritic mechanisms on phase response dynamics of GP neurons. 


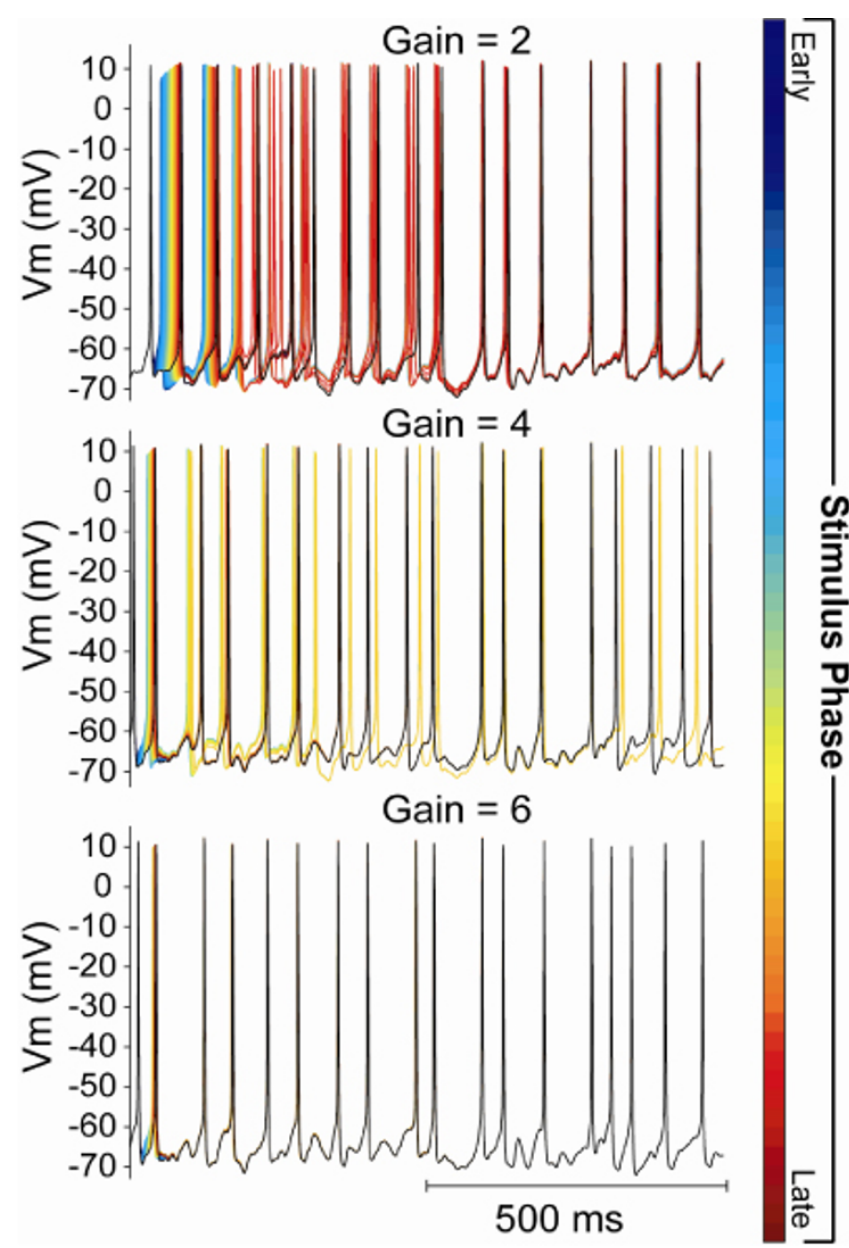

Figure I

Synaptic transients can yield long-lasting changes in spike pattern, but strong synaptic backgrounds force spiking quickly back to the control trajectory.
Publish with Bio Med Central and every scientist can read your work free of charge

"BioMed Central will be the most significant development for disseminating the results of biomedical research in our lifetime. " Sir Paul Nurse, Cancer Research UK

Your research papers will be:

- available free of charge to the entire biomedical community

- peer reviewed and published immediately upon acceptance

- cited in PubMed and archived on PubMed Central

- yours - you keep the copyright

Submit your manuscript here:

Submit your manuscript here:
http://www.biomedcentral.com/info/publishing_adv.asp 